Kohl: a Journal for Body and Gender Research

Vol. 3, No. 2 (Winter 2017)

\title{
Pornohealing:
}

\section{Pornography as a healing process for individuals with a history of sexual violence}

\author{
Sonia Patrinou
}

\begin{abstract}
:
By taking as a starting point "The Clit List," a pornographic database that includes porn material addressed to individuals who have experienced sexual harassment(s) and/or assault(s), this essay brings forward the following question: can pornography take the form of a healing process for individuals with a history of sexual violence? In order to provide an answer, alternative uses and aspects of pornography will be explored, with a particular focus on queer, feminist, and ethical porn. Following the contemporary history of pornography, I engage with both Queer Theory by discussing queer feminist approaches to porn, but also Affect Theory by sharing queer feminist approaches to trauma and the potential healing that an (erotic) film can induce in the spectator. More than simply seeking for alternative aspects of porn, this essay accounts for the (re)introduction of pornography as a productive media with a sexual healing possibility.
\end{abstract}

\section{Trigger Warning:}

This is a research article with specific reference to sexual violence. Though the focus is not given on the nature of the sexual harassment(s) and/or assault(s) that the individuals experienced, you might find some of the following material triggering. 


\section{Introduction 1}

It was almost two years ago that I discovered a British project named "My Body Back." This project offers to medical examinations to sexually assaulted women after the sexually violent incidents they have faced, in addition to group therapy sessions in order to provide them with psychological support. Apart from these activities, "My Body Back" also owns a pornographic database, which includes porn material addressed to women with a history of sexual violence, whether the violent incident was harassment or assault. This specific project is called "The Clit List" and provides sexual violence survivors with erotic media ${ }^{2}$ that might help them explore their sexual desires.

I found this pornographic database remarkably interesting and innovating, as I was already interested in alternative uses and aspects of pornography. But a specific research question was troubling my mind: could pornography take the form of a healing process for individuals with a history of sexual violence? The goal of my research is to examine whether people who experienced sexual harassment(s) and/or assault(s) watch feminist, ethical ${ }^{3}$ or queer ${ }^{4}$ non-triggering porn films, like the ones included in "The Clit List," so as to make themselves feel sexually aroused again after a traumatic event, redefine their approach to sexual activity in general, or just embrace body positivity.

This essay is divided into three main sections: the first introduces the contemporary history of pornography. In the second one, three different porn films are discussed, and finally, the third part includes an analysis of the results of a web-based survey that addresses the general awareness of feminist porn, but also the problem of accessibility to it. The survey is accompanied by three interviews that narrate the stories of people who experienced sexually violent incidents and their quite different preferences regarding porn, but also indicate the similarities regarding the political aspect of those preferences.

\footnotetext{
1 In the introduction of this essay, I will analyze what type of erotic media this project provides and the reasons why it differs from other pornographic databases.

2 According to the "My Body Back" project, "The Clit List" provides every individual who desires to explore their sexuality with non-misogynistic, feminist erotic media such as short and long porn films, erotic literature, photography, and so forth. By informing in detail the potential viewer regarding the porn film that they are interested in and by excluding violent or misogynistic content, they offer a non-triggering porn database - or at least a porn database that uses trigger warnings and consists only of feminist material - that covers a plethora of sexual preferences. For more information regarding the "My Body Back" project see: http://www.mybodybackproject.com/ (accessed August 31, 2017).

${ }^{3}$ Ethical porn is a spectrum of principles accompanied by a mentality that respects porn performers and treats them as employees, not only on set but also within the market. As a result, all the terms of the film - such as sexual acts or financial agreements - are consensual.

${ }^{4}$ In this essay, feminist, ethical, and queer pornography are not presented as a unanimous porn genre. These porn genres can stand alone or intervene with each other.
} 


\section{A Biography of Porn}

\subsection{Porn: The Golden Years}

The etymological origin of pornography comes from the Greek word pornographos. This term is actually a combination of two words: porne, which means prostitute, and graphein, which means to write. According to Debbie Nathan, U.S. feminist journalist and writer, "the word pornography first appeared in the Oxford English Dictionary in 1857, the same year that England passed a law banning the sale and distribution of sexual materials considered 'obscene'" (quoted in Wosick, 2015, p.414). The definition of this word has changed dramatically throughout the ages as a result of the different status and prestige that porne gained in contemporary societies. However, there is no consensus on how to define pornography per se; something perceived as pornographic material by one individual can be just sensual, erotic, or even artistic to another.

Where new technologies go, the porn industry is quick to follow. After the first pornographic post cards, pornography started to take its contemporary form: the production of the first hard core "stag" films begins to bloom during the early 1900s in America, according to Wosick (2015). Men's magazines like Hugh Hefner's Playboy (1953) or Bob Guccione's Penthouse (1969) become mainstream, and pornographic feature films are screened in American public theatres, such as Deep Throat (1972), The Devil in Miss Jones (1973), and Debbie Does Dallas (1978).

By the 1980s, video replaced film. In fact, the urban legend has it that VHS became the main standard of video cassette basically because the porn industry, which was already booming during the 1980s, adopted it and thus influenced the whole market. But, as a result, "high-value quality generally declined as more people made more porn more quickly - and often on a low budget. For this reason, the highvalue period prior to video production is known as pornography's golden era" (Tarrant, 2016, p.23).

However, the pornographic renaissance faced a plethora of obstacles. During the 1950s and 1960s, when conservative beliefs regarding gender and heteronormativity were dominant, as they still are today, some neo-Freudian arguments for "normal" sexual behavior started to gain public popularity, as Rebecca Sullivan and Alan McKee argue in Pornography. According to them, 1970 was the year that marked a heightening interest in pornography and its violent effects. ${ }^{5}$ That same year, the U.S. President's Commission on Obscenity and Pornography released a report regarding pornography and the repercussions of it on American citizens. Even though the findings of the Commission did not establish a conclusive link between pornography and violence, Jon Lewis observes that "the very fact that the question was posed cemented the link in the public's mind" (quoted in Sullivan and McKee, 2015, p.77). These anti-pornographic sentiments found space within feminist theories and politics, but not without generating internal conflicts. In this context, the so-called "sex wars" within feminisms took place.

\footnotetext{
5 Up until this point, I am referring to pornography as a whole and, to be more specific, to the type of pornography labeled as "mainstream." Of course, part of the concerns regarding the violent effects of pornography is justified; for example, the vast majority of women who enter the mainstream pornographic industry face sexploitation and victimization. However, later in this article it will become clear that I am focusing on specific pornographic genres that can potentially function as healing tools and not on every form of pornographic media.
} 


\subsection{The Sex Wars and Beyond}

The heteronormative frenzy that ensued contributed to the emergence of two sharply contrasting feminist camps: the anti-porn feminists and the pro-sex feminists. These feminist debates that first took place from the middle of the 1970s through the 1980s are known as "the sex wars." 6 According to Patrick Keilty (2012), anti-porn feminists such as Andrea Dworkin, Catharine MacKinnon, and Diana Russell declared that pornography (re)produces gendered power relations, promoting the heteronormative binary of men as sexual predators and women as passive sexual objects. Their critique on porn, especially mainstream hardcore porn, was valid when it comes to the (hetero)normative stereotypical roles of male and female porn performers, which actually reflects the societal gender binary and its (re)production.

However, radical ideas, such as the principle that women are oppressed by penetrative sex in general, or that there exists a causal and direct relation between pornography and rape, elicited a response from what came to be known as the pro-sex movement. Pro-sex feminists like Linda Williams, Drucilla Cornell, and Lara Kipnis joined arms with LGBTQAI+ individuals, women who were engaging in penetrative sex and/or BDSM practices, lesbian porn producers, and so forth, to take a stance against Dworkin's or MacKinnon's understandings of pornography.

Both sides contributed to generating a discourse around heteronormative pornography and its problematic aspects, but in no way can we compare these two movements equally; or, to use Gayle $\mathrm{S}$. Rubin's (1984, p.167) words, they cannot be characterized as "equally extremist." But what if the answer to mainstream heterosexual/heteronormative pornography might not be to forbid this erotic media in its entirety, but to create alternative porn genres that could and should portray more inclusive and diverse sexual acts, as well as reconceptualize penetrative sex itself? A queer approach to porn introduces a type of pornographic media with a distinct focus on the political. Queer porn differs from lesbian or dyke porn, ${ }^{7}$ as it does not only offer to the spectator screened sexual acts that were once deemed to be nonvisible, abnormal, or even not feminist. Instead, it attempts to thematize concepts of gender and racial identity, sexual orientation, and body positivity, and to make non-normative bodies and identities visible, thus potentially enabling a healing mechanism. Consequently, queer porn can be characterized not only as alternative because of its dyke imagery, but also as productive: the representation of those bodies operates as a healing tool, distinguishing queer porn from its pro-sex feminist genealogy.

6 For more information regarding the sex wars, see also the work of Heather Butler (2004), Drucilla Cornel (2000), Betty Dodson (2013), Jack Halberstam (1998), Patrick Keilty (2012), Lara Kipnis (1999), Gayle Rubin (1984), Ingrid Ryberg (2012), or Linda Williams (2004). For more information regarding the anti-porn feminist camp see Andrea Dworkin (1989), Catharine MacKinnon (1993), Robin Morgan (1982), or Diana Russell (2000). For a more contemporary view on anti-pornography feminism see also Gail Dines (2010) and Robert Jensen (1997).

${ }_{7}$ There is a differentiation between lesbian and dyke porn films. Lesbian porn, filmed between the 1970s and the 1980s, was characterized mostly by a softcore aesthetic and not penetrative sexual intercourse; The King (Looney Bear, 1968) or Erotic in Nature (Cristen Lee Rothermund, 1985) are examples of such lesbian porn films. On the contrary, dyke porn was appropriating sex acts that were considered to be heterosexual such as penetration, rough sex, or role-playing. A great example is the film Suburban Dykes (Debbie Sundahl, 1990), the first one to contribute to the pro-sex feminist dyke legacy. 
Another way that queer perspectives on porn proves the productiveness of this media lies in its DIY8 possibility. New technologies allow people to carve spaces of power in the production of porn. Paul Preciado 9 (2013, p.37) introduces the "autopornographic body" in Testo Junkie, ${ }^{10}$ a new force in the world-economy: "today, any user of the Internet who has a body, a computer, a video camera, or a webcam, as well as an Internet connection and a bank account can create a porn site and have access to the cyber market of the sex industry." Though Preciado refers to the autopornography industry as a potential sabotage to the monopoly of the big porn-corporations, the autopornographic body could also express a positively sexualized body. The plethora of amateur performers creating their own erotic films could potentially contribute to a body positive image. The feminist porn film collection Dirty Diaries: Twelve Shorts of Feminist Porn (Mia Engberg, 2009), ${ }^{11}$ a series of feminist porn shorts created by a group of artists, activists, and filmmakers financed by the Swedish state, is an example of this pornographic resistance.

Amateur porn production could indeed represent one way in which different body images are circulated, and the very profits of porn are redistributed outside the circuits controlled by porn-corporations. Nevertheless this essay focuses on a different way in which porn - whether amateur or not - might prove productive: that is, its potential contributions to healing processes.

\subsection{Pornography as a healing process}

Up until this point, the causal relation between porn and rape was one of the core claims of the anti-porn radical feminist camp. However, contemporary activist, scholarly, and cultural projects such as the London-based "My Body Back" project not only work to undermine the causal link between pornography and rape as posited by radical feminists as well as rightwing conservative critics of porn, but further suggest that pornography could work as a healing tool for people who experienced sexual violence.

Sexual violence can cause both physical and psychological pain and damage, and potentially negative effects on one's sexual expression; sexual harassment and/or assault can be a very traumatic experience. Griselda Pollock (2013, p.2) writes: "originating in the Greek word for what pierces the body, trauma originates as a medical term. (...) Events and assaults that cannot be processed, or 'digested' by the psychic apparatus are thus considered traumatic."

Nevertheless, trauma does not constitute a disorder or a form of disease; it entails experience and memory. As Pollock $(2013$, p.1) states, "trauma possesses and inhabits us." Consequently, trauma is not

\footnotetext{
8 Do It Yourself.

9 Paul Preciado published Testo Junkie: Sex, Drugs, and Biopolitics in the Pharmacopornographic Era in 2013, as Beatriz Preciado. But in 2014 Preciado announced that he was transitioning and, in January 2015, he changed his first name from Beatriz to Paul. As a result, I am referring to him as Paul but you can find the book in the list of references under the name Beatriz Preciado.

10 The book was first published in 2008 in Spanish, with title Testo Yonqui.

${ }^{11}$ I analyze Dirty Diaries at length, as well as erotic films in the second chapter.
} 
seeking for a cure; yet, it calls for a confrontation. In "An Archive of Feelings: Trauma, Sexuality, And Lesbian Public Cultures," Ann Cvetkovich addresses the problem of the pathologization of trauma and the sterilized clinical approach to it. In line with Judith Herman, Cvetkovich accounts for the political and social aspect of trauma, as the collective approaches to confront it can take the form of group therapy, the engagement and participation in feminist activist movements and groups, or acts like the "My Body Back" project.

Cvetkovich gives a specific example of public therapeutic confrontation of trauma by recalling the performance of Tribe 8, a dyke punk band, at the 1994 Michigan Womyn's Music Festival. During a workshop that followed their performance, Lynn Breedlove - lead singer of the band - "gave the group instructions on how to find cheap dildos to sacrifice and eloquently testified to the therapeutic power of mock castration" (Cvetkovich, 2009, p.73). Acts like the public castration of a dildo can help release physical tension and suppressed feelings; no longer perceived as violent expressions, they deal with internalized violence through therapeutic rituals instead.

Can pornography obtain effects similar to the performance of Tribe 8? Author and pro-sex feminist Donna Minkowitz "advocates of pro-sex lesbianism and S/M, and posits relations of dominance and submission as a mechanism for healing from incest rather than as its perpetration by other means" (Cvetkovich, 2009, p.75). Minkowitz argues that specific sexual practices might stimulate healing processes. Thus, pornography, as the ultimate form of erotic media and adult entertainment, could play a crucial role in confronting traumas related to sexually violent experiences. However, the question that arises is: could pornography as a whole contribute to the healing process of a sexual violence survivor or we should focus only on specific porn categories?

\section{Blue Filmography/Pink Politics ${ }^{12}$ \\ 2.1 Too much pussy? Much more pussy!}

Feminist, ethical, and queer pornography is characterized by certain political beliefs influenced by the feminist movement; it protects the porn performer, and aims to include individuals such as people of color, individuals with non-conforming/nonnormative gender identities and sexual orientations, people with functional diversity, or people with bigger bodies, scars, body hair and so forth. This heterogeneity of different types of bodies, sexualities, and gender identities promotes the visibility of people outside of the heteronormative context, which by itself entails a political message that could be in line with a healing aspect.

Examples of such films are Too Much Pussy: Feminist Sluts in the Queer X Show (2010) and Much More Pussy (2010), both directed by the French filmmaker Émilie Jouvet. Seven female performers from Europe and the U.S. traveled around Europe during the summer 2009, performing their burlesque show, The Queer X Show. Jouvet's films are a documentation of this tour, in addition to sexual intercourses

12 During the 1980's, pornographic content in video cassettes was sealed using a blue tape, hence people used to refer also to pornographic films as "blue films." The title of this chapter is a play between the color blue, signifying erotic films, and pink (politics) as a reference to the feminist, ethical, and queer aspect of the films discussed in the second section. 
between the members of the group and other queer individuals, as well as their engagement with other feminist, queer, and lesbian groups.

In the eight minutes of Much More Pussy, Sadie Lune, performer and sex educator, introduces herself and announces that she is going to show us her cervix. She spreads her legs and, with the help of a vaginal speculum and a mirror, she effortlessly presents her cervix to the rest of the female group and the camera. By this practice of auto-cervix examination, Lune aims to demedicalize this process.

According to Ingrid Ryberg (2012, p.84) the practice of cervix examination was made famous by Annie Sprinkle's "Public Cervix Announcements," staged through the 1990s, where "she invited members of the audience to her show Post Porn Modernist to look at her cervix through a speculum. In the case of The Queer X Show, explicit reference was made to 1980 s sex radicals such as Sprinkle." By embracing the practice of self-examination, and the exculpation of menstruation and female masturbation, a body and sex-positive movement arose during the 1980s, declaring the autonomy and the self-determination of the (female) body.

Can this body and sex-positivity, which infiltrates both Too Much Pussy and Much More Pussy, provide a therapeutic function for those women who have been sexually harassed and/or assaulted? Can this type of erotic films result into the creation of a pornographic safe space, where every individual is encouraged to express their sexuality and get to know their own bodies? As Ryberg (2012, p.34) states: "the interpretive community of queer, feminist and lesbian pornography is characterized by activist struggles aiming at constructing a safe space for sexual empowerment;" further, she explains "how this interpretive community functions both as an intimate public and as a counter public."

Following this concept, feminist, queer, and lesbian pornography might function as a safe space, where marginalized individuals, especially females, can finally share a sense of belonging. When Sadie Lune spreads her legs, stating her desire to know herself and what is going on inside her, she makes the point that sexuality is not something to be ashamed of. In doing so, she potentially helps every girl who has been sexually harassed and/or assaulted, from daily cat calls to actual rape, to realize that it is not her body that attracts those acts; rather, they are the results of an ailing patriarchal system.

\subsection{Silver Shoes}

Certainly, feminist porn is not only about politicizing sexual arousal. So, can feminist, ethical, and queer porn draw the political and the arousing together? And if so, should it turn exclusively toward nonnormative sexual identities and practices, or could acts as heterosexual penetrative sex be screened as well?

In Jennifer Lyon Bell's Silver Shoes (2015), three explicit erotic stories take place. The third one is that of Liandra, a bi/pansexual woman, who engages in sexual intercourse with her friend's male friend. This male friend is portrayed as a queer guy: he is the only guy in female company, and he talks about fashion; during one of the scenes, he wears a pair of silver high heels while executing a small catwalk for the amusement of his female friends. When the sexual encounter between the two performers takes place, 
Liandra is on top of her partner who looks like a young delicate boy, mesmerized by her. Although the sexual intercourse is a heterosexual one, Liandra seems to be in a position of power and dominance; she is offering and receiving pleasure at the same time to/from a man without being objectified. In this particular scene, the boundaries between the active and passive bodies are blurred. Bell manages to blend these two identities and offer an alternative representation of the intercourse that we call heterosexual sex. This blurring of the "roles" is one of the main concepts on which feminist, ethical, queer porn focuses. In doing so, it reconfigures or even extinguishes the active/passive binary.

Furthermore, the act of "topping" 13 itself can be quite therapeutic. For example, Cvetkovich summarizes Minkowitz's interesting argument on topping by reporting that she "characterizes her playful response to trauma as avoiding what she describes as the masculine pattern of passing on abuse by becoming a perpetrator. Topping, moreover, represents an alternative to the traditional 'female' response of adopting the position of 'victim,' which she identifies as the Dworkinite via negativa of refusing all association with anger and aggression" (Cvetkovich, 2009, p.75). Following Minkowitz, through the act of topping, the female partner puts aside the passive role, usually correlated to the bottom position, and adopts a more powerful one as a result. Thus, by watching a film that offers a different approach to heterosexual intercourse as Bell's Silver Shoes does, women who experienced sexual violence might find a way to reconceptualize the act of penetrative sex. Sex, and consequently porn, do not merely constitute the simplistic act of a male predator penetrating the female prey. Sex and pornographic films can be sensual, complex, spiritual, or romantic. ${ }^{14}$

\subsection{Dirty Diaries}

Authority (Marit Östberg, 2009), a short film in Dirty Diaries: Twelve Shorts of Feminist Porn (Mia Engberg, 2009), introduces obvious power relations regarding dominance and submission performed by individuals who engage in BDSM. ${ }^{15}$ Though this might be a controversial choice of queer porn with a potential healing aspect, engaging with more hardcore forms of queer pornography could be of relevance. So, what can $\mathrm{S} / \mathrm{M}$ practices offer to a sexual violence survivor?

In Authority, a policewoman is chasing a girl because she was making a graffiti on a wall. After the pursuit, they both end up inside an abandoned building, where the graffiti girl manages to tie the policewoman to a chair. The girl kicks the chair with the policewoman on it until it falls. Later, the girl lifts the chair up and unties the policewoman, who chooses to stay and, as a result, the erotic play between the two begins. Consent and trust are emphasized as a crucial aspect of BDSM play, two elements that are respected in

\footnotetext{
13 To sexually dominate someone.

${ }^{14}$ Apart from Silver Shoes, I generally suggest erotic films which are produced by the "Blue Artichoke Films" and directed by Jennifer Lyon Bell as she has a softer and romantic aesthetic in her films. Other examples of sensual and gentle intercourse in porn films can be found in The Good Girl (Erika Lust, 2004), Feeling It (Petra Joy, 2008) or Skin (Elin Magnusson, 2009).

15 The BDSM acronym stands for Bondage and Discipline (BD), Dominance and Submission (DS), Sadism and Masochism (SM). Although BDSM practices can include violent and painful acts, consent is the key factor of having a healthy and pleasurable BDSM sexual intercourse. However, consent is not just a matter of having a safe-word. Discussion, mutual understanding, and respect of one's limits in the context of power dynamics are a huge part of the whole BDSM mentality and that is exactly why BDSM practices could be applied as a form of sexual healing.
} 
this film because of the policewoman's decision to stay when she is finally untied.

This film is characterized by a certain complexity. First of all, it challenges the nature of the public space in relation to sex, as the whole BDSM session and the sexual intercourse take place in an abandoned building, and thus makes a clear reference to the demands of pro-sex activists during the sex wars regarding visibility. Furthermore, the two performers, a policewoman, who holds an authoritarian position, and the graffiti girl, who vandalizes public space, challenge each other's positions regarding dominance and submission by engaging in a BDSM sexual intercourse. Finally, the film strongly undermines prejudices about female sexuality, which is usually perceived as soft and romantic, by portraying a violent sexual play between two women.

In an interview that I conducted with Östberg, she argued that: "what [she] wanted to do, was to turn power structures upside down; this was a comment to [her] past as an activist. (...) So, the story in itself it is not healing, but it is political." Therefore, she wanted to play with these power structures by portraying a BDSM sexual interaction between a policewoman, a person of authority, and the graffiti girl, a person who violates the law. Following her own words, one can understand that there are distinctions lying between the intentions of the director and the impact that their creation(s) can have upon the audience. However, what Östberg created as an answer to the power imposed by the police can be perceived as a reenactment of a traumatic experience that challenges the person in authority and alters the roles but in a consensual way.

Keiko Lane, a Japanese American psychotherapist, shares the story of one of her first clients, a butchidentified dyke with a history of childhood sexual abuse, in "Imag(in)ing Possibilities: The Psychotherapeutic Potential of Queer Pornography." This butch dyke, who had dominant sexual fantasies, preferred porn made by and for men. As she admitted to Lane, her preference was simultaneously turning her on and making her feel guilty. Unfortunately, Lane admits that she ended up "[shaming her] in the ways in which she had been shamed by others" $(2013, p .167)$ because she was following the instructions of her supervisor in psychotherapy.

The main point made by Lane's supervisor was that (sexual) reenactments are always pathological and linked to traumatic experiences. Nonetheless, all of Cvetkovich's approach, Pollock's argument about trauma "inhabiting" us, and Minkowitz's support of S/M practices as healing mechanisms point to the confrontation and reenactment of trauma as an option. The reenactments of traumas can actually be therapeutic, because the traumatic experience is finally being faced in a conscious and controlled process.

Regarding porn's contribution, by identifying with a non-normative porn performer in a feminist, ethical, or queer film, through sexual acts considered to be non-conforming such as female topping, BDSM practices, gay sex, female ejaculation, and so forth, people who carry traumas related to their sexual expression can finally experience those covert fantasies and confront or reenact their stories through a liberating pornographic screening.

While films like Silver Shoes portray an emotional type of erotic films, Authority engages with BDSM practices and shows how queer BDSM porn films can be productive, as they allow for a reiteration of 
violence but in a safer consensual context. Queer lesbian porn can even be educative, as Much More Pussy teaches us. But do individuals who have experienced a form of sexual violence actually search for feminist, ethical, or queer porn? Do these persons find alternative types of pornography therapeutic? And to what extent is this type of porn accessible in the first place?

\section{Pornohealing: From theory to practice 3.1 Porn Taste: A Web-Based Survey}

The web-based survey that I created was posted in several Gender Studies and feminist groups on Facebook, addressed mostly to Dutch and Greek young people, because of my own identity as a Greek student in the Netherlands back then. Nevertheless, as these groups are open to every individual who is interested in feminism, LGBTQAI+ politics, and relevant news and events, 61 people from different countries all over Europe responded to the survey, 39 of whom were born between 1990 and 2000, and 22 between 1979 and 1989.

Regarding their gender and sexual orientation, $77 \%$ of the individuals identified as cis females, while $19.7 \%$ chose the answer "other" with responses that vary from queer to non-binary. Three cis males, a trans, ${ }^{16}$ and an intersex person also answered the questionnaire. With 27 individuals identifying as bi/pansexuals, we have to take into consideration the fact that most of the respondents are cis women interested in feminism and gender politics. Consequently, the combination of their own sexual orientation with their political views, which can be characterized as more open and non-normative, might result in a more open sexuality. ${ }^{17}$

Almost all of the respondents experienced sexual harassment, and most experienced sexual assault. The survey asked about their masturbation habits in order to examine whether they are facing difficulties or not, to later compare the results with their pornographic preferences, and the findings point to three people discontinuing their masturbation habits after the sexually violent incident they experienced.

When it comes to pornographic preferences, most state that they watch all kinds of porn mentioned mainstream heterosexual and gay porn, BDSM, and feminist, ethical, or queer porn, while $23 \%$ only watch feminist, queer, or ethical pornography, with $9.8 \%$, preferring BDSM porn exclusively. On whether the respondents started to prefer this type of porn after they experienced a form of sexual violence, $18 \%$

16 In the question regarding the gender identification, I gave the options of "cis female," "trans," "intersex," and "other." I chose not to divide the "trans" option between trans men and trans women because I wanted to include transgender individuals, people in transition who might not identify as one of the options mentioned above, or trans feminine/trans masculine individuals. However, if one desired to give a more specific answer they could choose the option "other" and write their own answer.

${ }^{17}$ As a pansexual myself, I believe that certain types of sexual orientation require some form of awareness and knowledge regarding other gender identities, for example. To call oneself pansexual requires an awareness of the fact that gender is not binary. And this is exactly why I stated that women who are attracted to more than one genders, through their studies or feminist beliefs, can be more open towards their attraction to individuals with a non-conforming gender identity because they acknowledge these gender identities in the first place. As a result, the fact that the majority of the cis female individuals who answered this questionnaire, and who are also members of feminist groups, identify as bi/pansexual is a quite reasonable percentage. 
answered affirmatively, and $16.4 \%$ argued that their interest in this type of porn is not linked to their history of sexual violence, or that they were not interested in mainstream porn even before the sexual harassment(s) and/or assault(s). But in order to understand whether there is a causal relationship between sexual violence and the preference of specific kinds of pornography or not, I had to examine the responses individually.

The vast majority of people who exclusively prefer feminist, ethical, or queer porn and/or BDSM porn have experienced sexual assault(s) or another form of sexual violence. The numbers indicate that the preferences in porn of the respondents who experienced a form of sexual violence and those who did not, vary. But all the persons who answered that they prefer exclusively feminist, queer, ethical porn or BDSM erotic films apart from one, do have a history of sexual violence. Only from this survey, one cannot be sure about the meaning of this preference. Speculations regarding the non-triggering nature of these alternative types of porn or the play on power dynamics in BDSM porn can be made, but of course further research on this topic is required in order to extract solid conclusions.

On the accessibility of this type of pornography, the vast majority of respondents have limited or no access to feminist, queer, or ethical porn. Subsequently, they turn to mainstream heterosexual or gay porn because they cannot afford a genre that, although they might consider to be of a better quality, remains expensive. It is worth noting that when it comes to education and employment, $98.4 \%$ of the respondents stated that they obtained BA or MA diplomas. Additionally, $52.5 \%$ out of the total are students, which raises the question of who is willing to pay for those types of pornography and who is not. Despite most of the respondents having a substantial socio-economic status, they still cannot or are not willing to pay in order to be able to watch some quality porn.

However, Jiz Lee, a queer porn performer, argues on their own website that "ethical porn starts when we pay for it" (Lee, 2015). As Lee states, without paying for pornographic films, you cannot be sure that basic labor rights have been respected during the production of the film. Not only does Lee focus on ethical porn, but on ethical porn consumption as well. Consequently, ethical porn does not concern the porn performers or the porn industry alone, as the spectator plays a crucial role. While many would prefer to invest their resources in other crucial consumption needs, even those who have the means for it do not conceptualize masturbation along with ethical porn as a necessity regarding their sexual activity.

\subsection{Interviews: sharing three stories}

The quantitative research has specific limitations, as neither does a survey allow the researcher to delve into the questions, nor does it deal with every person individually on a more coherent level. However, some of the respondents replied to my call for interviews. ${ }^{18}$ My first interviewee was a 32-year-old Greek cis man, living in Groningen, the Netherlands. He stated that he is heterosexual, but he would be open to engage in sexual acts with other male individuals. I will name him $X$. He was sexually harassed at twenty during a home party, where he was forced to take his clothes off in the context of a drinking game and several body shaming comments followed. I do not wish to focus further on the sexual harassment

${ }^{18}$ All of the interviews have been conducted through Skype in English. 
that $\mathrm{X}$ experienced, but it is important to state that sexual violence does not only take the form of rape, nor is it addressed specifically from male strangers to women walking down a street. Violence can take the form of a "game" among friends too, as X's story shows.

Regarding his pornographic preferences, $\mathrm{X}$ mentioned that he has watched almost every porn genre but he gradually started to look for more realistic or amateur porn. Erika Lust's films were one of his first experiences with feminist porn. When I asked him what he thought of the film, he replied: "I was a bit happy because it reminded me how I used to imagine being with a girl while not having a girl, when I was sixteen. What was happening was closest to how I used to set my mind (...) back when I [did not have] any computer."

The sexual harassment that $X$ experienced might not be directly linked to his porn preferences; further, he did not state that he sees a therapeutic aspect in alternative types of porn. However, he romanticizes feminist pornography, or at least Erika Lust's work. Cis men born and raised in a heteronormative patriarchal society can find feminist porn quite liberating for their stereotypical masculine identity, and this liberation from a set of macho rules and practices can be in itself therapeutic. But when it comes to crueler forms of sexual violence, like rape, can pornography really function as a therapeutic process? The stories shared by two cis female interviewees ${ }^{19}$ will allow the reader to navigate between the theoretical arguments and actual personal experiences, while I aim to answer the previous question as well.

Both of the girls I interviewed live in Greece, are BA students, and one of them also has a job. Y, twentythree years old, identifies as a bisexual woman while $Z$, twenty-two years old, mostly feels like a lesbian but she can have sex with cis men under specific circumstances. Both of them experienced childhood sexual abuse. Y's assaulter was a sixteen-year-old boy who also happened to be her neighbor, while $Y$ was around seven years old. $Z$ experienced two sexual assaults at the age of six and eight; first from her little cousin, and later from a sixteen-year-old teenager as well. Both $Y$ and $Z$ told me that these experiences were actually escalating practices, starting from inappropriate caresses and kisses and concluding to rape. It was very difficult for both of them to share these stories. $Z$ shared parts of these experiences with her mother some months ago, for the first time. Y's mother knows, but they barely talk about this incident.

Regarding their pornographic preferences, $Z$ does not often watch pornographic films. She prefers to fantasize and recall sexual acts that she experienced herself. She also states that she cannot be aroused by mainstream porn films because of their structure, and because "feelings" do not have a place in those films. As a feminist, she constantly analyzes these heteronormative stereotypes and structures, and this functions as a "turn off" for her. She is aware of feminist, queer, and ethical porn; nevertheless, she cannot access most of those films because she is not willing to pay. However, she would definitely prefer it if she could watch a feminist porn film for free. $Z$ has only watched parts of feminist or queer porn films, but when I asked her if she could find a therapeutic aspect in this genre, she gave me the following answer: "My answer would be hypothetical, but I think yes. I base this on how feminism and generally

19 Both of the interviewees are familiar faces. In this case, I consider it an advantage that both of them are known to me because of LGBTQAl+ and feminist circles in Athens, but our relationship would not be characterized as a friendship. As a result, mutual trust was already present, but also a certain distance between myself and the interviewees allowed for the interview to take place. 
queer [theory] offers tools and analysis about sexual stuff and trauma, and I have seen from my experience, involving in this kind of politics that I feel much better, safe."

Although $Z$ has a clear preference for feminist porn that stimulates emotions, it is difficult for her to afford it. On the other hand, $Y$ is mostly attracted to BDSM and male gay porn. She is also aware of feminist porn, but she has not had the chance yet to watch an erotic film of this type. Regarding gay porn, she prefers this genre because she does not enjoy watching female porn performers; the sexploitation of women in the porn industry turns her off. It is highly possible that $Y$ prefers gay male porn because it is performed between men: $Y$ feels alienated from those characters and can consequently enjoy the sexual acts between them.

When it comes to BDSM, $Y$ refers to this kind of porn and practices as a roleplay between two persons where "things are clear." When the individuals involved consent to each other's desires and acts, violence in fact can be quite liberating. Nevertheless, she admits that even BDSM is quite hard to watch sometimes. Furthermore, she expressed a type of guilt regarding her BDSM preference because as she said, "I also sometimes think that I may want to be dominant because of the sexual assault."

Y's answer is reminiscent of Lane's patient expressing the same feeling of guilt regarding her BDSM porn preference. While Lane is invested in the psychotherapeutic impacts that queer pornography can have on people with a history of sexual violence, the key is to find the right type of pornography for them. If we combine the results of the survey regarding the exclusive preference for alternative types of pornography or BDSM erotic films along with the arguments of the interviewees, especially Y's and Z's, we can see a pattern regarding the severity of the sexual violent incident(s) that those persons experienced and their switch to or conscious preference for feminist, queer, and ethical porn or BDSM. Though the stories of $Z$ and $Y$ share a similar experience of childhood sexual abuse, they have very different preferences when it comes to pornographic films, regardless of the similarities of the sexual assaults and their common political beliefs. However, both of them are close to the two sub-categories of the survey of people with a heavy history of sexual violence who also tend to prefer feminist or BDSM porn. Consequently, I conclude that for a considerable number of people, the severity of the sexual violence that they experienced is a decisive factor regarding their present pornographic preferences, which seem to be expressed through feminist, queer, and ethical porn, or BDSM erotic films and practices.

\section{Conclusion}

To summarize, the responses to the survey and the interviews that have been conducted, show that especially people who experienced some form of sexual violence would prefer to watch feminist, queer, or ethical porn, but financial transactions that are almost always required for this specific kind of porn operate as a limiting factor. However, paying for the porn that we watch might actually constitute the key factor for a more qualitative as well as ethical porn industry. Additionally, many of the women who have been sexually assaulted, such as Z, argued that they could see themselves in this type of pornography, something that could potentially function as a healing process for them. One cannot give a straight answer to the question of whether feminist, ethical, or queer porn can really take the form of a healing process for people with a history of sexual violence, but it definitely aids in the effort to eliminate toxic normative 
stereotypes and rape culture. It is also quite positive that most of the respondents to the survey, along with the three interviewees, knew about feminist, ethical, and queer porn already, either because of their feminist political identity or due to articles on online magazines. This is a proof that feminist, ethical, and queer porn is gaining in popularity, which can result in a lot of positive potential regarding the image and the perception of our bodies, and the expression of our sexuality.

As a concluding note, I would like to point out that all of the interviews required emotional investment from both parts - the one who narrates and the one who listens - and I am incredibly thankful to all of my interviewees. I can only express my admiration for the courage they showed upon sharing their experiences not only with me, but with every potential reader of this essay.

Finally, this research topic could and should be further discussed, but space limitations do not allow for further analysis. However, in the future, I wish for this topic to be to examined from a more intersectional perspective by including categories such as race and ability in relation to the subject of sexual violence and the potential healing aspect of pornography. 


\section{References}

Butler, H. (2004) "What Do You Call a Lesbian with Long Fingers? The Development of Lesbian and Dyke Pornography" In: Williams, L. (ed.), Porn Studies, 1st ed. Durham and London: Duke University Press, pp. 167-197.

Cvetkovich, A. (2003) An Archive of Feelings: Trauma, Sexuality, and Lesbian Public Cultures, Durham and London: Duke University Press.

Keilty, P. (2012) "Embodiment and Desire in Browsing Online Pornography" In: Proceedings of the iConference, [online] Available at: http://works.bepress.com/patrick_keilty/4 (accessed on 21 June 2017).

Lane, K. (2013) "Imag(in)ing Possibilities: The Psychotherapeutic Potential of Queer Pornography" In: Tristan, T., Parreñas Shmizu, C., Penley, C., and Miller-Young, M. (eds.), The Feminist Porn Book, 1st ed. New York: The Feminist Press, pp. 164-178.

McKee, A. and Sullivan, R. (2015) Pornography: Structures, Agency and Performance, Cambridge: Polity Press, pp.74-102.

Pollock, G. (2013) After-Affects, After-Images, Manchester: Manchester University Press, pp.1-33.

Preciado P. (2013) Testo Junkie: Sex, Drugs, and Biopolitics in the Pharmacopornographic Era, New York: The Feminist Press, pp. 23-54.

Rubin, G. (1984) "Thinking Sex: Notes for a Radical Theory of the Politics of Sexuality" In: Aggleton, P. and Parker, R. (eds.), Culture, Society and Sexuality, 2nd ed. London: Routledge, pp. 150-187.

Ryberg, I. (2012) Imagining Safe Space: The Politics of Queer, Feminist and Lesbian Pornography, Stockholm: Acta Universitatis Stockholmiensis.

Tarrant, S. (2016) The Pornography Industry, New York: Oxford University Press.

Wosick, K. (2015) "Pornography" In: John DeLamater, J. and Plante, R. (eds.), Handbook of the Sociology of Sexualities, 1st ed. Switzerland: Springer International Publishing, pp. 413-434.

\section{Webography}

Lee, J. (2015) Ethical Porn Starts When We Pay For It, [online] Jiz Lee, Available at: https://www.jizlee.com/ethical-porn-consumption-pay-for-porn-anti-piracy/) (accessed 4 September, 2017)

Mybodybackproject.com, (2017) About The Clit List [online] Available at: http://www.mybodybackproject.com/about-the-clit-list/ (accessed on 4 September, 2017)

\section{Filmography}

Dirty Diaries (2009) [film] Sweden: Mia Engberg

Erotic in Nature (1985) [film] USA: Cristen Lee Rothermund

Much More Pussy (2010) [film] France: Émilie Jouvet

The King (1968) [film] USA: Looney Bear

Too Much Pussy: Feminist Sluts in the QueerX Show (2010) [film] France: Émilie Jouvet

Silver Shoes (2015) [film] The Netherlands: Jennifer Lyon Bell 
